Journal of Social Sciences 4 (3): 173-177, 2008

ISSN 1549-3652

(C) 2008 Science Publications

\title{
Favorableness-Reality Index
}

\author{
Mahmoud Ahmadinejad and Jalal Ayoubinejad, \\ Mojtaba Maghrebi and Mahmoud Reza Keymanesh \\ Department of Construction Engineering and Management, \\ Iran University of Science and Technology (IUST), Iran
}

\begin{abstract}
By constructing a systematic structure of processes, decision models would give the most comprehensive and appropriate decision out of the variety of choices. As an instance, Analytic Hierarchy Process model (AHP) has helped to perfect interpretation and systematic decision. Application of this model in control process and evaluation of organization performance were investigated. The opinion of senior chief managers and mid managers about organizational priorities in terms of plan's elements and organizational politicians was gathered via inquiring forms and real performance was specified. The results were analyzed by AHP model and finally, FavorablenessReality Index (FRI) was defined for performance evaluation. For instance, implementation plan of quality management system in a consulting firm was perused.
\end{abstract}

Key words: FRI, AHP, organization performance, quality management

\section{INTRODUCTION}

Successful accomplishment of program starts with program itself. It is obvious that if the program were not realistically, applicable and recognizable, it would not lead to success. Mentioning this point is perquisite that the favorable results are achieved only and only if the program was adjusted by considering the capacity and organization resource ${ }^{[4]}$. Effective observation and coordination in the accomplishment of the program belongs to the persistent revision of project progresses and fulfillment the entire objectives of the program. This revision instigates accountable units to accomplish their program and to ensure their responsibilities. The privilege is that this inspection is for identifying actual situation and deviations recognition resulted from the program purposes to take necessary action to modify these activities ${ }^{[5]}$. Different factors cause incompatible coordination between the designed and rendered program. Among these factors, the following can be pointed $^{[6]}$ :

- Wrong information and incorrect decision in process of preparing program

- Prohibitive and unsuitable action pending the program production

- Changing situations and external conditions
One of the ways to control the organization is the performance evaluation that can be done in three following ways ${ }^{[6]}$ :

- Evaluation before the performance

- Evaluation through the performance

- Evaluation after the performance

Performance evaluation should not only be the form of assessment and reporting aspects, but the results should be used to improve the functions. Briefly it means that evaluation performance after function is to procure the feedback and return the decision results to the decision makers and identify the weak and powerful points and revising through the program function.

Also ordinary methods used to evaluate reporting disciplines and questionnaires or the combination of both. Evaluating units should determine the type of necessary information and the reports that received from operational units should be analyzed and the results containing the qualities of what have been done, insufficiencies, obstacles and problems before organizations. In this way, physical and pecuniary index could be used while these indexes demonstrate the performance of different parts of the organization.

Corresponding Author: Jalal Ayoubinejad, Department of Construction Engineering and Management, Iran University of Science and Technology, Iran Tel: 00989125074204 


\section{FAVORABLENESS-REALITY INDEX}

Each manager needs sufficient understanding about the style and the organization function and the decisions corresponding to the deduction of current situation about the objectives and the programs and even the priorities and ultimately the activities should be controlled and evaluated ${ }^{[7]}$. In this manuscript a model was proposed by taking the advantages of Analytic Hierarchy Process ${ }^{[8]}$ which went through organization performance. For this purpose, first of all, it was required to divide each proposal and plan to its smaller components that were called activity units. Activity unit was part of the plan that could be analyzed independently and taken a decision about it.

Then by use of questionnaires, it will be evaluated the priority of a unit in relation with other one. The manager by considering the recognition of organization, available resources and anticipated planning, clarify the importance and priority of each units. Pertain to that, AHP was used to achieve the final weight of each unit. This calculated weight was called management favorableness weight. It means each plan components in the organization senior manager's point of view had their own priority and especial weight. Although, the intentions and requirements in the orientation of these plan exploitation would be calculated quantitatively.

It needed to evaluate activities after, before and during the plan functions. It should be identified whether during the implementation of plan in organization, activity units were considered equal anticipated importance or not. In other hand, in this stage, the deviation from favorable situation was assessed. It was accomplished by surveying mid managers, staff and other hand holders about activity units and devoted values to each of them in the body of organization. Requisite data acquisition was also done by questionnaires and other additional weight would achieved by using AHP. The final weight was called executive reality weight. These two calculated weights for the activity units ware numbers between zero and one.

The index for assessing the performance of each activity was defined by using these two mentioned weights. It could be entitled as favorableness-reality index in this script. FRI is obtained from Eq. 1.

$$
\text { FRI }=\frac{\text { management favorable weight }}{\text { executive reality weight }}
$$

If the index was less than one, it means the related operational unit was preferred more than its favorable value or importance during performing in an organization. Also, if the index was greater than one, it means that the operational unit was less preferred than its favorable value and importance in the body of organization. Besides if the index was equal one, it means that the operational unit function exactly as it was preferred. Therefore, an auxiliary tool for controlling and assessing the executive operation was achieved. By index distinction of the activity units, the manager should revise the distracted activity units and apply one of the following trends:

- Decreasing the level of activity

- Performing activities as previous

- Increasing the level of activity

Whenever decreasing the activity level was needed, the manager should prevent organization resources despoiling by justifying other mangers and staffs and present the requisite remedial ways oriented to the predicted goals. Whenever increasing the level of activity was needed, the manager should provoke the sensitivity of mid-managers and other staffs unit to roll and accomplish approach to the better and more exact execution of recipes. The achieved results of favorableness-reality index was investigable in other point of view. This index helps manager to discern his correct decision. In spread organization that there were plenty of resources and organization goals, organization recognition, performance diagnostic, goals determination and resource allocations were very difficult. It caused that manager mislead to incorrect decision and the management favorable weight that defined, was not proportional to organization resources and performance feasibility was not achieved as necessary. In this case, the corrective action was needed to the more peruse and investigation till conduce to the suitable decision and application. It means that if a manager made any mistake in his recognition, he amended his visions and therefore the new favorable weights would be defined for that operational units and if the manger believed that his decision was true and distinguished that the organization current processes were not favorable, he should identify the source of distraction and corrective action should accomplished.

\section{CASE STUDY: EVALUATION OF ORGANIZATION PERFORMANCE IN CONSULTING FIRM}

During last two decades, using quality management systems has developed rapidly and its application causes growth of quality, process, performance and products $^{[2]}$. Quality means the correspondents between 


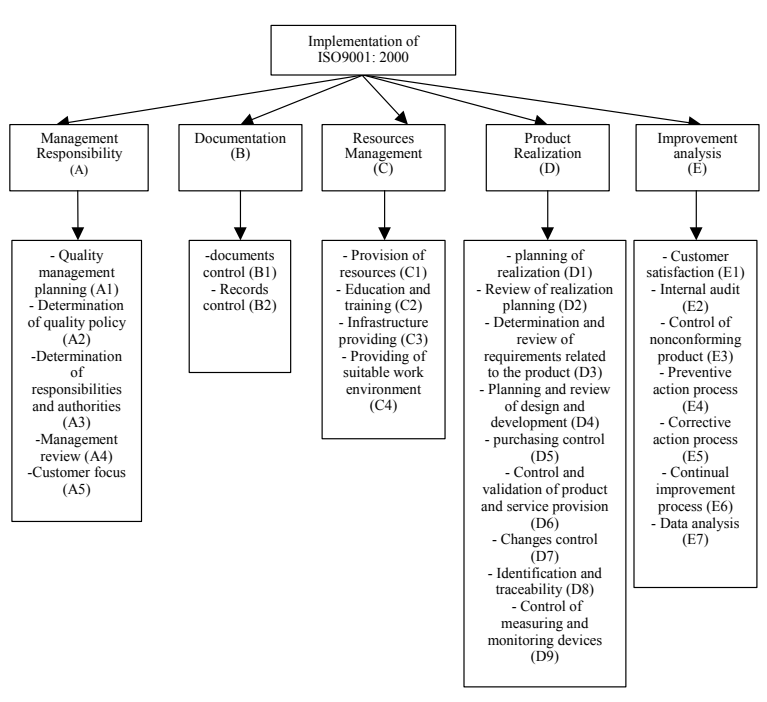

Fig. 1: Activity units for implementation plan of quality management system

customer needs and a product or service without imperfection ${ }^{[1]}$. Therefore, implementing the quality management systems plans is a kind of impressive and important plans of any organization.

In this part, it was declared how to use favorableness-reality index in organization performance evaluation in the implementation of quality management systems.

As previously mentioned, the first step to evaluate organization performance, by FRI index, was dividing the plan to the activity units. After studying details of the plan and surveying programs in an organization to implement the plan of quality management system, activity units of the mentioned plan and its criteria and relevant sub criteria was defined. These units were shown in Fig. 1.

The second step was to take the organization senior managers opinions about the importance and value of each activity units to reach the anticipated goals of the plan. This data was extracted from questionnaire forms and while manager express his opinions by the pairwise comparison and ultimately favorable management weight for each units was determined by using the AHP model. In Table 1, an example of designed questionnaire was prepared. This table was used for pairwise comparison among criteria. Hence it was assumed if the value of the first criteria was equal one, what would be the value of the next criteria in the comparison with the first? After performing a plan in an organization through questionnaires, the opinion of executive and mid managers about all activity units was taken. Then by using geometric average ${ }^{[3]}$, synthesis of
Table 1: Questionnaire sample for pairwise comparison

\begin{tabular}{llll}
\hline Criteria & Value & Criteria & Value \\
\hline A & 1 & B & $?$ \\
A & 1 & C & $?$ \\
A & 1 & D & $?$ \\
A & 1 & E & $?$ \\
B & 1 & C & $?$ \\
B & 1 & D & $?$ \\
B & 1 & E & $?$ \\
C & 1 & D & $?$ \\
C & 1 & E & $?$ \\
D & 1 & E & $?$ \\
\hline
\end{tabular}

Table 2: Management favorable weight and executive reality weight for each activity unit

\begin{tabular}{|c|c|c|c|c|}
\hline \multicolumn{2}{|c|}{$\begin{array}{l}\text { Management favorable } \\
\text { weight for activity units }\end{array}$} & \multicolumn{2}{|c|}{$\begin{array}{l}\text { Executive reality weight } \\
\text { for activity units }\end{array}$} & \multirow[b]{2}{*}{ FRI } \\
\hline Level 1 & Level 2 & Level 1 & Level 2 & \\
\hline \multirow{6}{*}{$\mathrm{A}=0.455$} & & $\mathrm{~A}=0.381$ & & 1.194 \\
\hline & $\mathrm{A} 1=0.180$ & & $\mathrm{~A} 1=0.124$ & 1.452 \\
\hline & $\mathrm{A} 2=0.031$ & & $\mathrm{~A} 2=0.027$ & 1.148 \\
\hline & $\mathrm{A} 3=0.142$ & & $\mathrm{~A} 3=0.103$ & 1.379 \\
\hline & $\mathrm{A} 4=0.059$ & & $\mathrm{~A} 4=0.061$ & 0.967 \\
\hline & $\mathrm{A} 5=0.009$ & & $\mathrm{~A} 5=0.016$ & 0.563 \\
\hline \multirow[t]{3}{*}{$B=0.045$} & & $\mathrm{~B}=0.047$ & & 0.957 \\
\hline & $\mathrm{B} 1=0.034$ & & $\mathrm{~B} 1=0.026$ & 1.308 \\
\hline & $\mathrm{B} 2=0.011$ & & $\mathrm{~B} 2=0.021$ & 0.524 \\
\hline \multirow[t]{5}{*}{$\mathrm{C}=0.249$} & & $\mathrm{C}=0.279$ & & 0.892 \\
\hline & $\mathrm{C} 1=0.044$ & & $\mathrm{C} 1=0.068$ & 0.647 \\
\hline & $\mathrm{C} 2=0.037$ & & $\mathrm{C} 2=0.036$ & 1.028 \\
\hline & $\mathrm{C} 3=0.153$ & & $\mathrm{C} 3=0.147$ & 1.041 \\
\hline & $\mathrm{C} 4=0.015$ & & $\mathrm{C} 4=0.028$ & 0.536 \\
\hline \multirow[t]{10}{*}{$\mathrm{D}=0.155$} & & $\mathrm{D}=0.205$ & & 0.756 \\
\hline & $\mathrm{D} 1=0.013$ & & $\mathrm{D} 1=0.014$ & 0.928 \\
\hline & $\mathrm{D} 2=0.004$ & & $\mathrm{D} 2=0.006$ & 0.666 \\
\hline & $\mathrm{D} 3=0.030$ & & $\mathrm{D} 3=0.042$ & 0.714 \\
\hline & $\mathrm{D} 4=0.028$ & & $\mathrm{D} 4=0.043$ & 0.651 \\
\hline & $\mathrm{D} 5=0.010$ & & $\mathrm{D} 5=0.015$ & 0.666 \\
\hline & D6 $=0.012$ & & D6 $=0.017$ & 0.705 \\
\hline & $\mathrm{D} 7=0.027$ & & $\mathrm{D} 7=0.028$ & 0.964 \\
\hline & $\mathrm{D} 8=0.023$ & & $\mathrm{D} 8=0.031$ & 0.742 \\
\hline & $\mathrm{D} 9=0.006$ & & $\mathrm{D} 9=0.009$ & 0.666 \\
\hline \multirow[t]{8}{*}{$E=0.096$} & & $E=0.089$ & & 1.079 \\
\hline & $\mathrm{E} 1=0.004$ & & $\mathrm{E} 1=0.003$ & 1.333 \\
\hline & $\mathrm{E} 2=0.024$ & & $\mathrm{E} 2=0.022$ & 1.091 \\
\hline & $\mathrm{E} 3=0.009$ & & $\mathrm{E} 3=0.012$ & 0.750 \\
\hline & $\mathrm{E} 4=0.005$ & & $\mathrm{E} 4=0.005$ & 1.000 \\
\hline & $\mathrm{E} 5=0.010$ & & $\mathrm{E} 5=0.009$ & 1.111 \\
\hline & $\mathrm{E} 6=0.021$ & & $\mathrm{E} 6=0.018$ & 1.167 \\
\hline & $\mathrm{E} 7=0.023$ & & $\mathrm{E} 7=0.020$ & 1.150 \\
\hline
\end{tabular}

judgments was realized and the executive reality weight for each activity unit was calculated with AHP. Therefore the favorableness-reality index for each activity units could be calculated. The calculated parameters of the mentioned firm have shown in Table 2. The Fig. 2, shown the discrepancy between the two calculated weight and Fig. 3, shown the achieved index of each activity units and even showed the discrepancy value from one. 


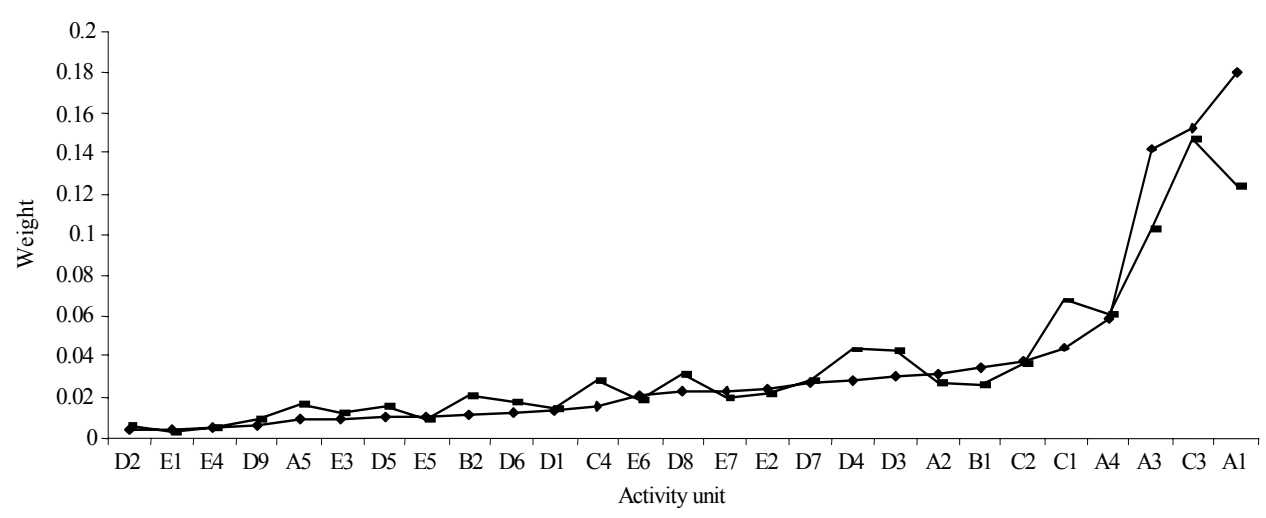

Fig. 2: Discrepancy between the two calculated weights

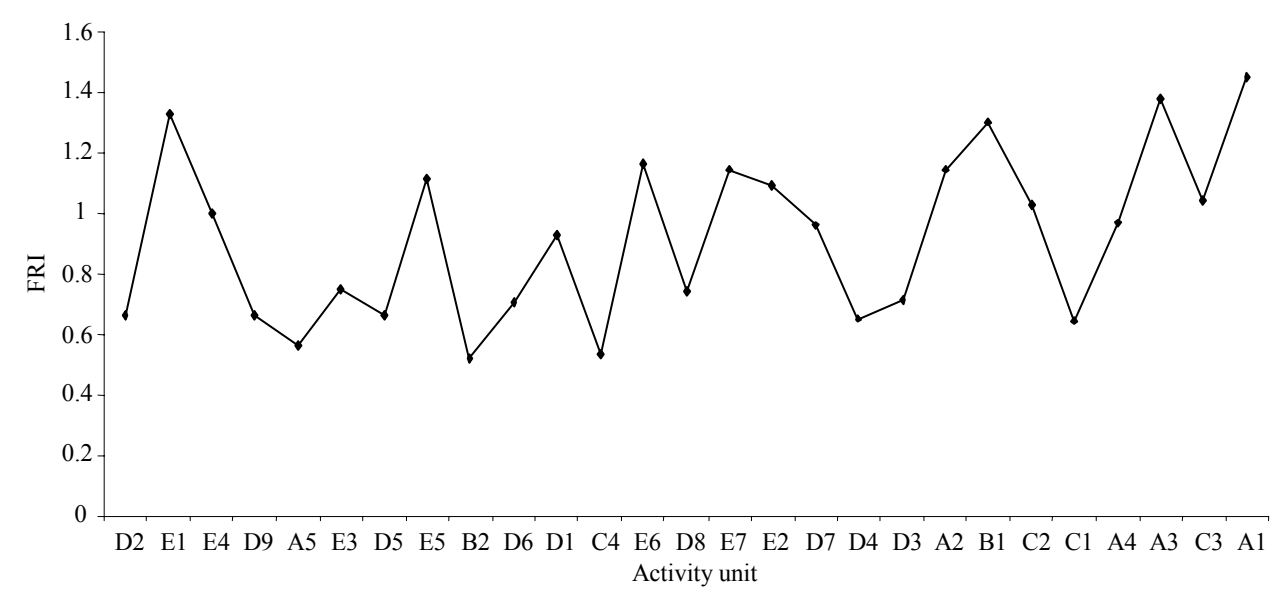

Fig. 3: FRI for each activity unit

\section{RESULTS AND DISCUSSION}

Table 2 shown that the Documentation activity and improvement analysis were generally correspondent to the managing policies. Resources management and product realization were accomplished more than its favorable limit which has spoiled organization resources. FRI for management responsibility showed that activity performance in the organization was less than what was forecasted and the manager should acquaint the mid managers and employees about the importance of this activity. Also, same analysis could be determined for other criteria.

\section{CONCLUSION}

- Favorableness-reality index can be implementing as a control and performance evaluation tool for each organizational activity unit
- This index cozily assesses the implementation portion of senior managers' policies and planning in an organization

- Because of this method, distractive units from expected values in organization main policies are easily distinguished and assessed

\section{REFERENCES}

1. Arditi, D. and H.M. Gunaydin, 1997. Total quality management in the construction process. J. Project Manage., 15 (4): 235-243.

2. Chin, K. and T. Choi, 2003. Construction in Hong Kong: Success factors for ISO9000 implementation. J. Construct. Eng. Manage., 129 (6): 599-609.

3. Aczel, J. and T. Saaty, 1983. Procedure for synthesizing ratio judgments. J. Math. Psychol., 27: 93-102. 
4. Marris, P. and J. Pinto. 2006. The Wiley Guide to Management Projects. 1st Edn. John Wiley and Sons, Inc., New York.

5. Harsey, P. and K. Blanchard, 1988. Management of Organizational Behavior Utilizing Human Resources. 5th Edn. Perentice-Hall International Editions.

6. United Nation, 1978. Department of Technical Cooperation for Development. Guide lines for development planning: Procedures, methods and techniques.
7. Karzner, H., 2003. Project Management: A System Approach to Planning, Scheduling and Controlling. 8th Edn. John Wiley and sons, Inc., New York.

8. Saaty, T.L., 1980. The Analytic Hierarchy Process. 1st Edn. McGraw-Hill, New York. 